\title{
Efektivitas Model Pembelajaran Make A Match terhadap Hasil Belajar pada Materi Balok Kelas VIII
}

\author{
${ }^{1}$ Hepi Gustia, ${ }^{2}$ Hariani Juwita, ${ }^{3}$ Jemiyo Siswanto \\ 1,2,3 STKIP Muhammadiyah Pagaralam, Sumatera Selatan \\ Email penulis pertama: happygustiyah1@gmail.com
}

\begin{abstract}
The purpose of this study was to examine the effectiveness of mathematics learning through the Make A Match Effective Learning Model for class VIII students of SMP Negeri 1 Tanjung Sakti PUMU in the 2017/2018 academic year. The population in this study were all students of grade VIII SMP Negeri 1 Tanjung Sakti PUMU in the 2017/2018 academic year (165 students), the samples taken in this study were randomly assigned. So class VIII4 was chosen as the control class as many as 32 students, class VIII5 as the experimental class as many as 35 students with a total of 67 students. Data collection was taken by using the test method in the form of essays, while the data analysis used quantitative descriptive, namely hypothesis testing with the $t$ formula ( $t$-test statistics). After the research was held, it was found that 70.01> 64.53 then Ho was rejected Ha accepted.
\end{abstract}

Keywords: Effectiveness, Make A Match Learning Model, Learning Outcomes

\begin{abstract}
Abstrak
Tujuan dari penelitian ini adalah untuk mengetahui keefektivan pembelajaran matematika melalui Model Pembelajaran Make A Match Efektif pada siswa kelas VIII SMP Negeri 1 Tanjung Sakti PUMU Tahun Pelajaran 2017/2018. Populasi dalam penelitian ini adalah seluruh siswa kelas VIII SMP Negeri 1 Tanjung Sakti PUMU Tahun Pelajaran 2017/2018 yang berjumlah 165 siswa, sampel yang diambil dalam penelitian ini secara acak (random). Maka terpilihlah kelas VIII4 sebagai kelas kontrol sebanyak 32 siswa, kelas VIII5 sebagai kelas eksperimen sebanyak 35 siswa dengan jumlah keseluruhan penelitian ini 67 siswa. Pengumpulan data diambil dengan metode tes dalam bentuk essay, sedangkan analisis data menggunakan deskriptif kuantitatif yaitu uji hipotesis dengan rumus $\mathrm{t}$ (statistik uji t). Setelah diadakan penelitian maka didapat yaitu 70,01 > 64,53 maka Ho ditolak Ha diterima.
\end{abstract}

Kata kunci: Efektivitas, Model Pembelajaran Make A Match, Hasil Belajar

Copyright (c) 2021 Gustia, Juwita, Siswanto

Corresponding author:

Email Address: happygustiyah1@ gmail.com

Received 25 Juli 2018, Accepted 24 Februari 2021, Published 28 Februari 2021

\section{PENDAHULUAN}

Balok adalah bangun ruang tiga demensi yang dibentuk oleh tiga pasang persegi atau persegi panjang dengan satu pasang diantaranya berukuran berbeda. Balok memiliki 6 sisi, 12 rusuk, dan 8 titik sudut (kiri dan kanan) Salamah (2015:194). Menurut Effendi (2017), materi kubus merupakan salah satu materi matematika yang terdapat pada kompetensi dasar yang harus dikuasai siswa kelas VIII dan erat kaitannya dengan kehidupan sehari-hari. Kubus dan balok merupakan bangun ruang yang sering ditemui siswa dalam kesehariannya, seperti pada saat siswa akan membungkus hadiah dengan kotak yang biasanya berupa balok.

Menurut Mutia (2017) menyatakan bahwa kesulitan dalam belajar adalah siswa belum dapat menemukan unsur-unsur balok seperti titik sudut, rusuk dan lainya. Siswa masih menyamakan istilah sisi dalam bangun datar dengan bidang sisi pada bangun ruang. Siswa juga sulit memahami bidang diagonal itu bentuknya seperti bangun datar apa, ada yang menyebut jajar genjang padahal tentunya 
persegi panjang. Selain itu, kurangnya hasil belajar siswa karena metode selama ini kurang bervariasi, guru cenderung lebih mengarah pada pemberian pengetahuan dari guru kepada siswa, sehingga siswa berpatokan kepada apa yang dijelaskan oleh guru saja.

Mata pelajaran matematika sebaiknya diberikan kepada semua peserta didik mulai dari sekolah dasar yang memiliki tujuan antara lain yaitu membekali peserta didik dengan kemampuan berfikir logis, analitis, sistematis, kritis dan kreatif serta kemampuan berkerja sama. Hal ini sesuai dengan standar kompetisi dan kompetisi dasar matematika sebenarnya yang telah disusun dalam dokomen Kurikulum Tingkat Satuan Pendidikan (KTSP) sebagai landasan pembelajaran untuk mengembangkan kemampuan tersebut. Sesuai Permendiknas nomor 23 Tahun 2006 yang menyatakan tentang Standar Kompetensi Lulus (SKL). Sementara itu matematika merupakan salah satu mata pelajaran yang diujikan secara nasional, maka seluruh kompetensi yang ada harus dikuasai siswa, sehingga hasil belajar siswa mencapai standar kompetensi lulus yang di tetapkan. Salah satu model pembelajaran yang dapat digunakan untuk membuat matematika tidak menyulitkan bagi siswa sekaligus melibatkan siswa aktif dalam pembelajaran yaitu model pembelajaran make a match (mencari pasangan). Make a match merupakan model pembelajaran yang digunakan untuk memberikan konsep pemahan materi yang sulit kepada siswa serta dapat digunakan untuk mengetahui sejauh mana pengetahuan dan kemampuan siswa dari materi tersebut. Model pembelajaran ini dipopulerkan oleh Lorna Curran tahun 1994 Zarkasyi (2017:75).

Menurut penelitian yang sudah dilakukan Mikran, Pasaribu, \& Wayan (2013) Hasil penelitian menunjukan bahwa penerapan pembelajaran make a match dapat meningkatkan hasil belajar fisika siswa kelas VIIA SMP Negeri 1 Tomini. Menurut Milaturrahmah, Ahmad \& Rizki (2016) dapat disimpulkan bahwa pada model pembelajaran kooperatif tipe make a match lebih tinggi atau lebih baik dari pada pembelajaran konvensional dalam meningkatkan hasil belajar matematika. Hal ini berarti ada pengaruh model pembelajaran kooperatif tipe make a match terhadap hasil belajar. Dalam penelitian Maulizar (2016) dapat disimpulkan bahwa penerapan model pembelajran Make a match terhadap peningkatan hasil belajar biologi pada materi tumbuhan biji (Spermatophyta) dapat meningkatkan hasil belajar siswa kelas VII di SMP N kb. Tanjong Kabupaten Pidie. Berdasarkan uraian diatas penelitian ini bertujuan untuk mengetahui keefektivan pembelajaran matematika melalui Model Pembelajaran Make A Match Efektif pada siswa kelas VIII.

\section{METODE}

Metode penelitian pada dasarnya merupakan cara ilmiah untuk mendapatkan data. Data yang diperoleh melalui penelitian itu adalah data teramati yang mempunyai kriteria tertentu yaitu valid (Sugiono, 2013:02). Berdasarkan pendapat diatas metode yang digunakan dalam penelitian ini adalah tes serta penelitian ini dilihat dari jenisnya merupakan penelitian deskriftif kuantitatif. Dalam penelitian peneliti mengadakan eksperimen dengan mengajar di kelas-kelas yang menjadi sampel. Kelas tersebut yaitu kelas eksperimen dan kelas kontrol. Ekseperimen adalah suatu cara untuk mencari sebab akibat 
antara dua faktor yang sengaja ditimbulkan oleh peneliti dengan mengeliminasi atau mengurangi atau menyisihkan faktor - faktor lain yang mengganggu. Ekperimen dilakuukan dengan maksud untuk melihat akibat dari suatu perlakuan (Arikunto, 2014: 9).

Penelitian ini menggunakan desain Pretest Posttest Design, Desain penelitian ini digunakan karena penelitian ini menggunakan kelompok kontrol, adanya dua perlakuan yang berbeda, dan pengambilan sampel secara acak kelas. Tes matematika di lakukan satu kali yaitu sesudah proses pembelajaran, yang disebut postes. Secara singkat desai penelitian tersebut adalah sebagai berikut.

\begin{tabular}{cccc}
\hline $\mathrm{E}$ & $\mathrm{O}_{1}$ & $\mathrm{X}$ & $\mathrm{O}_{2}$ \\
\hline $\mathrm{K}$ & $\mathrm{O}_{3}$ & $\mathrm{X}$ & $\mathrm{O}_{4}$
\end{tabular}

Keterangan :

E : Kelompok Eksperimen

K : Kelompok Kontrol

O1 : Pretest (test awal) dilakukan pada pertemuan pertama untuk mengetahui hasil belajar siswa pada kelas eksperimen.

O2 : Posttest (test akhir) dilakukan pada akhir pertemuan untuk. Mengetahui seberapah besar siswa dapat menyerap materi yang telah disampaikan dan untuk mengetahui seberapa efektifnya kemampuan siswa pada kelas eksperimen.

O3 : Pre-test

O : Post-test

\section{HASIL DAN DISKUSI}

\section{Deskripsi Pelaksanaan Pembelajaran}

Pelaksanaan kegiatan pembelajaran di kelas VIII5 dengan menerapkan model pembelajaran Make A Match pada materi balok. Setelah membuka pembelajaran dengan mengucapkan salam, peneliti memperkenalkan diri dan peneliti memeriksa kehadiran siswa, dengan tujuan untuk mengenal siswa. Setelah itu peneliti memberikan soal pretest kepada siswa secara individu. Setelah itu peneliti menjelaskan tentang sifat-sifat balok, kemudian peneliti melakukan proses belajar mengajar dengan model pembelajaran Make A Match dengan langkah-langkah sebagai berikut:

1. Peneliti menyiapkan beberapa kartu yang berisi beberapa konsep atau topik yang cocok untuk sesi review, sebaliknya satu bagian kartu soal dan bagian lainnya kartu jawaban, kemudian peneliti membagi kelompok yang dipilih secarah acak setiap kelompok terdiri dari 2 sampai 3 orang siswa.

2. Setiap kelompok mendapatkan satu buah kartu, dimana satu kelompok ada yang mendapatkan kartu soal dan ada yang mendapatkan kartu jawaban. Setiap kartu yang telah dibagikan mempunyai pasangan jawaban yang cocok dengan soal yang ada pada kartu. Terlihat seperti gambar 1 berikut: 


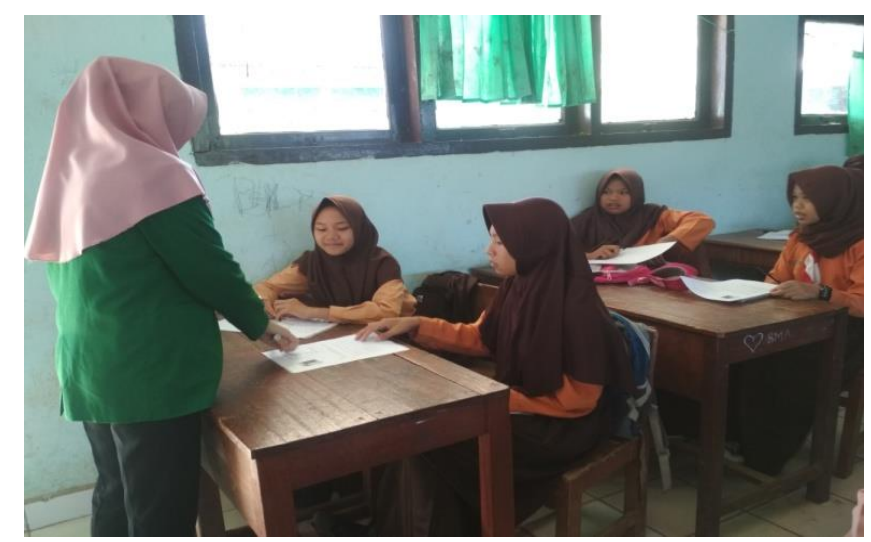

Gambar 1. Peneliti Membagikan Kartu Yang Berisi Soal dan Jawaban

3. Tiap kelompok mencari jawaban atau soal dari kartu yang di dapat, dalam tahap ini setiap kelompok dituntut untuk berpikir atas jawaban soal yang mereka dapat. Peneliti berusaha memotivasi peserta didik untuk menjawab pertanyaan terkait dengan balok yang telah mereka kerjakan pada tiap kartu. Aktivitas ini dapat dilihat pada gambar 2 berikut:

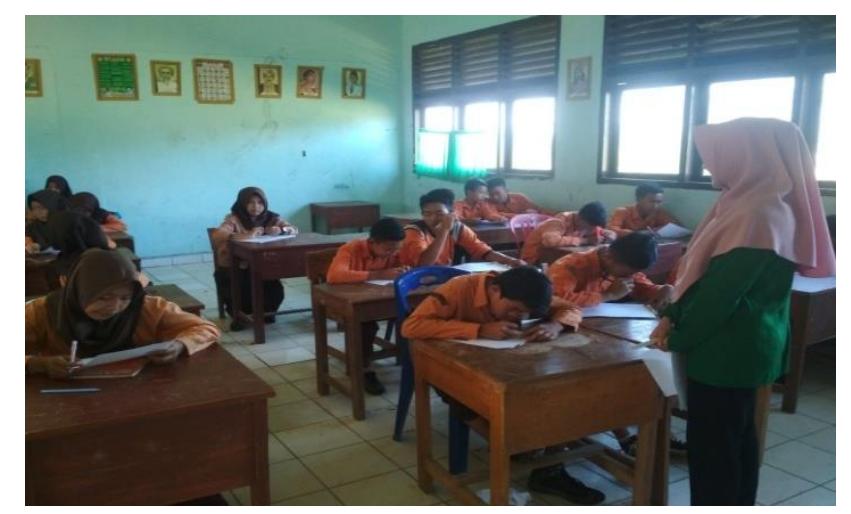

Gambar 2 Siswa Menyelesaikan Soal atau Jawaban pada Kartu

4. Setelah semua kelompok telah mengerjakan soal yang ada pada kartu dengan batas waktu yang telah ditentukan, kemudian setiap kelompok mencari pasangan yang mampunyai kartu yang cocok dengan kartunya (soal-jawaban). Setiap kelompok terlihat antusias untuk mencari pasangan dari kartu yang mereka kerjakan. Peneliti memberikan point kepada setiap kelompok yang berhasil mendapatkan pasangan dari soal yang mereka kerjakan dalam batas waktu yang telah ditentukan. Dari aktivitas ini terlihat semua siswa ikut aktif didalam proses pembelajaran .

5. Setelah satu babak kartu dikocok lagi agar tiap kelompok mendapat kartu yang berbeda dari sebelumnya. Hal ini dilaksanakan agar setiap siswa mendapatkan semua soal atau jawaban yang telah dibuat oleh peneliti. Sehinga, semua kelompok mempunyai kesempatan untuk menjawab semua soal atau jawaban pada kartu. Demikian seterusnya sampai semua kelompok mendapatkan soal atau jawaban yang berbeda-beda.

6. Langkah terakhir yaitu kesimpulan atas apa yang telah dipelajari melalui media kartu soal-jawaban. Peneliti bersama siswa menyimpulkan materi yang telah dipelajari tentang balok. Kemudian 
peneliti memberikan kesempatan kepada siswa untuk bertanya tentang materi yang belum dimengerti. Aktivitas ini dapat dilihat pada gambar 3 berikut:

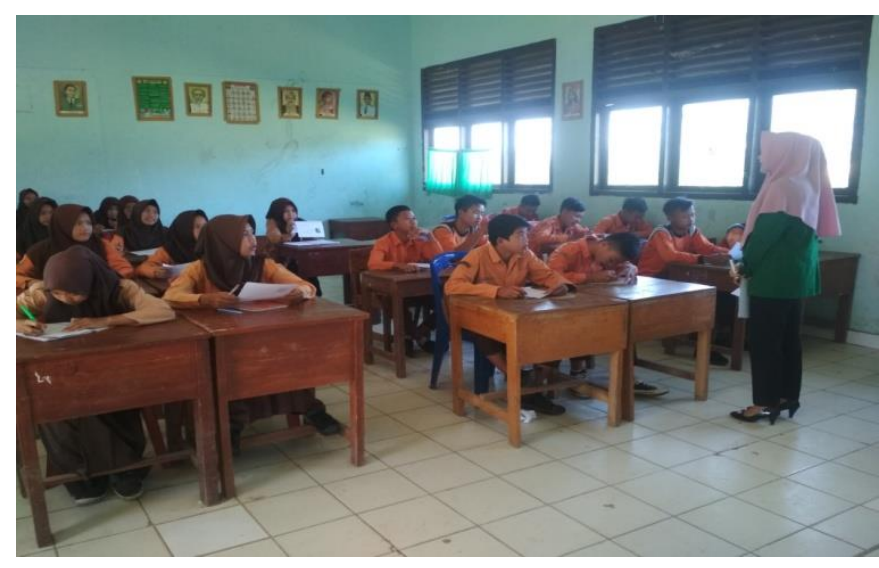

Gambar 3. Peneliti Dan Siswa Menyimpulkan Materi Yang Telah Dipelajari

Pertemuan kedua masih menggunakan model pembelajaran Make a Match. Cara pembelajaran sama pada pertemuan pertama, hanya saja dipertemuan kedua ini yang akan dibahas adalah materi mencari rumus volume serta menggunakan rumus untuk menghitung volume Balok. Pertemuan ketiga digunakan untuk post-test.

\section{Hipotesis}

Sebelum dilakukan pembelajaran menggunakan model pembelajaran Make A Match, siswa diberi pre-test setelah itu dilakukan pembelajaran tersebut yang selanjutnya siswa diberikan post-test. Pre-test dibandingkan dengan post-test untuk melihat perbedaanya Hepotesisi nol yang diuji dengan $\mathrm{H}_{0}$ : Model pembelajaran Make A Match tidak efektif terhadap Hasil Belajar Matematika siswa pada materi balok di kelas VIII SMP Negeri 1 Tanjung Sakti PUMU Tahun Pelajaran 2017/2018. Sedangkan Ha: Model pembelajaran Make A Match efektif terhadap Hasil Belajar Matemetika siswa pada materi balok di kelas VIII SMP Negeri 1 Tanjung Sakti PUMU Tahun Pelajaran 2017/2018. Untuk menguji hopotesis, terlebih dahulu akan dilakukan uji prasyarat yaitu uji normalitas. Untuk mengetahui normalitas data nilai kemampuan komunikasi matematika siswa pada pre-test dan post-test memakain uji chi kuadrat.

\section{Uji Homogenitas Pre-test}

Uji homogenitas dua varians pretest dilakukan untuk mengetahui apakah kedua sampel yakni kelas eksperimen dan kelas kontrol tingkat variannya sama (homogen) atau tidak Dengan taraf signifikan $5 \%$. Untuk mengetahui homogenitas ini dilakukan menggunakan uji $f$. 


\begin{tabular}{cc}
\hline $\begin{array}{c}\text { Kelas VIII } \\
\text { (Eksperimen) }\end{array}$ & Kelas VIII \\
\hline$n_{1}=35$ & $n_{2}=32$ \\
\hline $\bar{x}_{1}=46,11$ & $\bar{x}_{2}=47,81$ \\
\hline$s_{1}^{2}=163,634$ & $s_{2}^{2}=140,39$ \\
\hline
\end{tabular}

Tabel 1. Rata-rata dan Simpangan Baku Pree-test

$$
f=\frac{\text { varianterbesar }}{\text { varianterkecil }}=\frac{163,634}{140,39}=1,17
$$

Dari hasil perhitungan $f_{\text {hitung }}=1,17$ sedangkan $f_{\text {tabel }}$ dengan taraf signifikan $5 \%$ dk penyebut $=(35$ $1)=34 \mathrm{dk}$ pembilang $\mathrm{dk}=(32-1)=31$, didapat $f_{\text {tabel }} 1,80$. Maka $f_{\text {hitung }}=1,17<f_{\text {tabel }}=1,80$. Jadi dapat disimpulkan bahwa kedua kelas sampel homogen. Karena kedua kelas tersebut mempunyai data yang homogen maka kelas tersebut dapat dijadikan sampel penelitian.

\section{Uji Homogenitas Post-test}

Uji homogenitas dua varians dilakukan untuk mengetahui apakah kedua sampel yakni kelas eksperimen dan kelas kontrol tingkat variannya sama (homogen) atau tidak Dengan taraf signifikan 5 $\%$. Untuk mengetahui homogenitas ini dilakukan menggunakan uji $f^{\text {` }}$

\begin{tabular}{cc}
\hline Kelas VIII (Eksperimen) & Kelas VIII $\mathbf{4}$ (Kontrol) \\
\hline$n_{1}=35$ & $n_{2}=32$ \\
\hline $\bar{x}_{1}=70,01$ & $\bar{x}_{2}=64,53$ \\
\hline$s_{1}^{2}=123,37$ & $s_{2}^{2}=147,55$ \\
\hline
\end{tabular}

Tabel 2. Rata-rata dan Simpangan Baku Post-test

$$
f=\frac{\text { varianterbesar }}{\text { varianterkecil }}=\frac{147,55}{123,37}=1,20
$$

Dari hasil perhitungan $f_{\text {hitung }}=1,20$ sedangkan $f_{\text {tabel }}$ dengan taraf signifikan $5 \%$ dk penyebut $=(35$ $1)=34 \mathrm{dk}$ pembilang $\mathrm{dk}=(32-1)=31$, didapat $f_{\text {tabel }} 1,84$. Maka $f_{\text {hitung }}=1,20<f_{\text {tabel }}=1,84$. Jadi dapat disimpulkan bahwa kedua kelas sampel homogen. Karena kedua kelas tersebut mempunyai data yang homogen maka kelas tersebut dapat dijadikan sampel penelitian.

\section{Pengujian Hipotesis}

Dari hasil perhitungan diperoleh hasil nilai rata-rata dan standar deviasi siswa yang pembelajarannya menggunakan model pembelajaran Make a match dan siswa yang pembelajarannya tidak menggunakan model pembelajaran Make a match, maka didapat: 


\begin{tabular}{cc}
\hline Kelas VIII (Eksperimen) & Kelas VIII (Kontrol) $^{\text {(E) }}$ \\
\hline$n_{1}=35$ & $n_{2}=32$ \\
\hline $\bar{x}_{1}=70,01$ & $\bar{x}_{2}=64,53$ \\
\hline$s_{1}^{2}=123,37$ & $s_{2}^{2}=147,55$ \\
\hline$s_{1}=11,11$ & $s_{2}=12,15$ \\
\hline
\end{tabular}

Dengan menggunakan uji kesamaan rata-rata uji t satu pihak, diperoleh rumusan hipotesis sebagai berikut:

$\mathrm{H}_{o}: \mu_{1}=\mu_{2}$ : Model pembelajaran Make A Match tidak efektif terhadap Hasil Belajar Matemetika siswa pada materi balok di kelas VIII SMP Negeri 1 Tanjung Sakti PUMU Tahun Pelajaran 2017/2018.

Ha : $\mu_{1}>\mu_{2}: \quad$ Model pembelajaran Make A Match efektif terhadap Hasil Belajar Matemetika siswa pada materi balok di kelas VIII SMP Negeri 1 Tanjung Sakti PUMU Tahun Pelajaran 2017/2018.

$t_{\text {hitung }}=1,96$ dan $t_{\text {tabel }}=1,668$. Setelah memperoleh $t_{\text {hitung }}$ dan $t_{\text {tabel }}$ selanjutnya peneliti melakukan pengujian hipotesis dengan kriteria pengujian hipotesis yaitu Ho diterima jikadk, dimana $t_{(1-\alpha)}$ didapat dari daftar distribusi t dengan $\left(\mathrm{dk}=n_{1}+n_{2}-2\right)$ dan taraf signifikan $\alpha=0,05$. Kurva untuk harga-harga t lainya $H_{0}$ ditolak (Sudjana 2005:239)

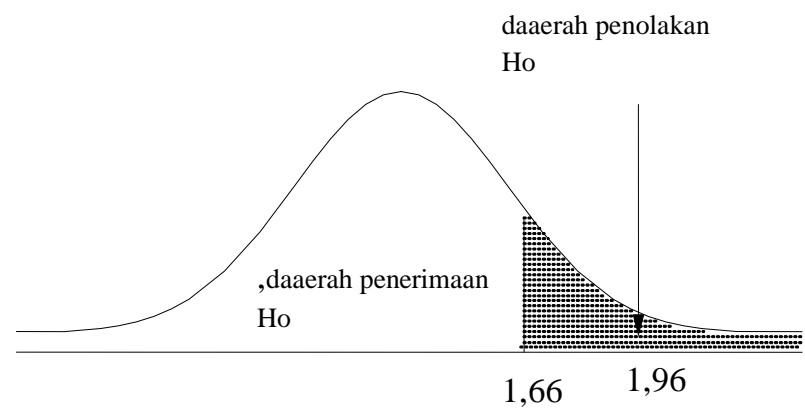

Gambar 4. Kurva Daerah Pengujian Hipotesis

Berdasarkan pengujian hipotesis diatas didapatkan nilai t hitung sebesar 1,96 dan t tabel sebesar 1,668 jadi $t$ hitung $>t$ tabel yang berarti bahwa $\mathrm{H}_{\mathrm{a}}$ dapat diterima kebenarannya dan $\mathrm{H}_{0}$ ditolak. Dengan demikian dapat disimpulkan bahwa model pembelajaran make a match efektif terhadap hasil belajar matematika siswa pada materi balok di kelas VIII SMP Negeri 1 Tanjung Sakti PUMU Tahun Pelajaran $2017 / 2018$.

\section{KESIMPULAN}

Berdasarkan analisis data pada bab IV sebelumnya maka peneliti dapat menyimpulkan bahwa Analisis data di dapat thitung sebesar 1,96 dan ttabel sebesar 1,668 menurut kriteria pengujian jika 
thitung $=1,96>$ ttabel $=1,668$, ini berarti $\mathrm{H0}$ di tolak dan Ha diterima. Jadi strategi pembelajaran Make A Match efektif terhadap hasil belajar siswa pada materi balok di kelas VIII SMP Negeri 1 Tanjung Sakti PUMU Tahun Pelajaran 2017/2018. Karena kemampuan siswa dalam memahami dan menerima pembelajaran dengan model pembelajaran Make A Match di kelas VIII SMP Negeri 1 Tanjung Sakti PUMU sudah cukup baik, hal ini bisa dilihat dari nilai rata-rata yang di dapat sebesar 70,01 sedangkan nilai rata-rata siswa tidak menggunakan model pembelajaran Make A Match yaitu 64,53.

\section{REFERENSI}

Arikunto, Suharmisi, (2014). Prosedur Penelitian Suatu Pendekatan Praktek. Jakarta: Rineka Cipta.

Effendi, K. N. S. (2017). Pemahaman Konsep Siswa Kelas VIII pada Materi Kubus dan Balok, Pasudan Journal of Research in Mathematics Learning and Iducation, Vol.2 No.2

Mikran. Pasaribu \& Wayan (2011), Penerapan Model Pembelajaran Kooperatif Make A Match untuk Meningkatkan Hasil Belajar Siswa Kelas VIIA SMP Negeri 1 Tomini Pada Konsep Gerak. Jurnal Pendidikan Fisika Tadulako (JPFT) Vol. 2 No. 2, ISSN: 2338-3240.

Mutia. (2017). Analisis Kesulitan Siswa SMP dalam memahami konsep kubus balok dan alternatif pemecahannya, Jurnal Tadris Matematika, vol. 10, no.1, diakses pada tanggal 23 maret 2018

Salamah, Umi.(2015). Matematika. Solo: PT Tiga Serangkai Pustaka Mandiri.

Sugiyono. (2012). Metode Penelitian Kuantitatif, Kualitatif dan $R \& D$. Bandung: Alfabela.

Zarkasyi, Wahyudin. (2017). Penelitian Pendidikan Matematika. Bandung: PT Resfika Aditama 